\title{
O USO DE REDES SOCIAIS VIRTUAIS PELOS IDOSOS
}

\author{
Michelle Cristina Ferreira ${ }^{1}$ \\ Karla Maria Damiano Teixeira²
}

resumo

Frente às mudanças na estrutura populacional, somada às alterações tecnológicas advindas do crescimento da utilização de redes sociais virtuais (RSV) no dia a dia das pessoas, faz-se necessário uma melhor compreensão sobre o uso destas redes por idosos. Para realizar tal análise, é de grande relevância que se aprofundem estudos sobre os fatores que motivam esse público ao uso das RSV. A academia começou a explorar as características dos usuários de RSV e os motivos de sua utilização. No entanto, a maioria dos estudos tem se limitado a estudar um grupo específico de usuários - os jovens deixando, dessa forma, lacunas a respeito de outros grupos etários, como os idosos. Além disso, há um enfoque em tecnologia e inovação e não especificamente na utilização somente de RSV. Nesse contexto, surgiu o interesse em conduzir uma pesquisa com o objetivo de identificar as principais motivações que levam os idosos a adotarem o uso de RSV em seu cotidiano. Para isso, foi realizada uma pesquisa exploratória descritiva, de natureza qualitativa com uma amostra de

1 Graduada em Administração. Mestra em Economia Doméstica. E-mail: michellecfadm@gmail.com. 2 Graduação em Economia Doméstica. PhD em Ecologia Familiar pela Michigan State University. Professora Associada da Universidade Federal de Viçosa, vinculada ao Departamento de Economia Doméstica. E-mail: kdamiano@ufv.br. 
21 idosos que possuem perfil em RSV. Os resultados apontaram que uso das RSV proporciona aos idosos, experiências positivas, principalmente relacionadas como um recurso para entretenimento e contato com familiares e amigos. A facilidade de comunicação favorece para que os idosos possuam uma maior e melhor rede de relações, em especial, para que o contato com a família ocorra com mais facilidade e que a saudade entre os membros seja minimizada.

palavras-chave

Idoso. Redes Sociais Virtuais. Relações Familiares.

\section{Introdução}

A sociedade vivencia um processo de envelhecimento e esse novo paradigma tem inspirado a realização de estudos em diferentes áreas do conhecimento. Todavia, as pesquisas desenvolvidas sobre essa temática, por muitos anos, se mostraram repetitivas (KALACHE, 2008), estão mais voltadas para os problemas enfrentados pelos idosos decorrentes do processo de envelhecimento, enfatizam os desafios inerentes à idade e, ressaltam, assim, os estereótipos negativos da velhice (CAMARANO, 2011). Poucos estudos visam compreender os aspectos positivos do envelhecimento (MONTAÑA; ESTANYOL; LALUEZA, 2015; GAIKAR, 2015; ROSENBERG, 2013; FIORE, 2009), havendo, portanto, uma lacuna a ser preenchida.

Em paralelo ao processo de envelhecimento da população, encontram-se as inovações tecnológicas e, em especial, as tecnologias de comunicação e informação (TIC), influenciando a sociedade e o modo de vida das pessoas (AZEVEDO; CÔRTE, 2009). Dentre as TIC, têm-se os sites de redes sociais virtuais (RSV), disponibilizados por meio da internet, que são ferramentas com o objetivo de estímulo à comunicação, permitindo a interação e conexão entre pessoas, a construção de redes sociais e o estabelecimento de suporte social com a finalidade de difundir informações de vários conteúdos (CARVALHO, 2009).

Por meio das RSV são introduzidas novas formas de comunicação, atraindo diferentes públicos, inclusive os idosos. O percentual de usuários idosos dessas redes é o que mais cresce mundialmente. Nos Estados Unidos, $45 \%$ da população idosa utiliza uma RSV; na Itália esse percentual corresponde a 32\% e, na África do Sul, a população idosa representa $24 \%$ dos usuários de RSV 
(PEW RESEARCH CENTER, 2010). Quando analisados os dados brasileiros, este crescimento de usuários idosos de RSV representa cerca de $2 \%$ ao ano, ou seja, um aumento de 66\% entre 2007 e 2013 (IBGE, 2015).

Frente às mudanças na estrutura populacional, somada às alterações tecnológicas advindas do crescimento da utilização das RSV, no dia a dia das pessoas, faz-se necessário uma melhor compreensão sobre o uso destas redes por idosos (BARBOVSCHI; MACHÁČKOVÁ; ÓLAFSSON, 2015). Para realizar tal análise, é de grande relevância que se aprofundem estudos sobre os fatores que motivam esse público ao uso das RSV.

A temática RSV, mesmo que moderadamente, vem atingindo espaço nas pesquisas acadêmicas em âmbito internacional e nacional. Autores como Ridder e Van Bauwel (2015); Chan-Olmsted, Cho e Lee (2013); Lewis e Ariyachandra (2011); Ariyachandra, Crable e Brodzinski (2009), Resende et al. (2007), entre outros, constataram em pesquisas relacionadas ao tema, que se trata de um campo de estudo embrionário que apresenta diversas possibilidades de pesquisa, bem como limitações que precisam ser trabalhadas e superadas.

Nesse contexto, faz-se importante identificar e entender as principais motivações que levam os idosos a adotarem o uso de RSV em seu cotidiano. Tal análise se faz importante, pois os resultados encontrados em pesquisas já realizadas indicaram a necessidade da realização de estudos mais aprofundados sobre a temática. Além do mais, essa pesquisa pode contribuir para estudos referentes a envelhecimento e qualidade de vida, já que a utilização das RSV pode favorecer para que os idosos superem as barreiras sociais e espaciais de interação social por meio da facilidade de comunicação e entretenimento a qualquer hora e lugar (CHEN; SCHULZ, 2016).

\section{Procedimentos metodológicos}

Essa pesquisa, exploratória descritiva e de natureza qualitativa (GIL, 2008), foi realizada na cidade de São Gotardo, localizada na região do Alto Paranaíba, no estado de Minas Gerais. A população foi constituída por idosos, conforme a classificação do Estatuto do Idoso (BRASIL, 2003), de ambos os sexos, lúcidos e que possuíam acesso à RSV. A pesquisa se desenvolveu pela técnica de amostragem bola de neve (snowball). Participaram da pesquisa, 21 pessoas idosas, sendo 14 do sexo feminino e 7 do sexo masculino, com idade mínima de 60 e máximo de 83 anos (com o nascimento entre 1934 e 1957), sendo a média de idade de 67 anos. 
A coleta de dados se valeu da combinação de técnicas, a saber: teste de memória para avaliar se os idosos estavam aptos a participar da pesquisa e entrevistas fundamentadas em um roteiro semiestruturado, que foram gravadas com a permissão dos participantes. As entrevistas foram realizadas entre o período de dezembro/2016 e fevereiro/2017.

Uma vez realizadas, as entrevistas foram transcritas de forma integral, gerando o corpus da análise, ou seja, o conjunto representado pelos dados obtidos pela pesquisa. A análise foi realizada por meio da análise de conteúdo proposta por Bardin (2009). Em respeito aos entrevistados, os seus nomes foram resguardados. Dessa forma, foram utilizadas para representar os participantes a letra " $\mathrm{A}$ " acompanhada de um número cardinal, que diz respeito a ordem em que a entrevista foi realizada. Faz-se importante mencionar que esse trabalho foi submetido e aprovado pelo Comitê de Ética em Pesquisas com Seres Humanos da Universidade Federal de Viçosa (2014), pelo número de parecer 1.821.644. Por meio desses procedimentos metodológicos foi possível a exposição dos dados de forma mais concisa e fluída, conforme os resultados apresentados a seguir.

\section{Resultados e discussão}

\subsection{Os Idosos e Uso de Redes Sociais Virtuais}

Participaram da pesquisa 21 pessoas idosas, sendo 14 do sexo feminino e 7 do sexo masculino, com idade mínima de 60 e máximo de 83 anos. No que se refere à escolaridade dos participantes, verificou-se que: 6 idosos não concluíram o ensino fundamental; 4 haviam concluído o ensino fundamental; 5 possuíam o ensino médio completo e; 6 haviam concluído o ensino superior, desses, 3 possuíam pós-graduação Lato Sensu e 01 pós-graduação Stricto Sensu (nível doutorado).

Inicialmente, identificou-se as principais RSV utilizadas pelos idosos, o principal meio de acesso, os dias da semana e turno em que eles as utilizam, além da quantidade de tempo gasto e principal função utilizada. A principal rede social utilizada foi o WhatsApp, que era utilizada por todos os idosos estudados, seguido do Facebook (Tabela 1). 
Tabela 1 - Principais RSV utilizadas pelos participantes, São Gotardo/MG, 2017.

\begin{tabular}{|l|l|}
\hline \multicolumn{1}{|c|}{ Redes sociais virtuais } & \\
\hline WhatsApp & 21 \\
Facebook & 17 \\
Messenger & 11 \\
Instagram & 8 \\
Snapchat & 5 \\
Linkedln & 2 \\
\hline
\end{tabular}

Fonte: Tabela elaborada pelos autores, 2017.

A preferência pelo uso do WhatsApp pelos participantes foi justificada pela facilidade de uso. Em geral, os idosos o descreveram como o aplicativo com os recursos mais simples, além de destacarem sua facilidade para comunicação. No que se refere aos meios de acesso, os 21 participantes declararam acessá-las por meio do Smartphone. Entretanto, salientaram que também gostam de acessá-las por meio de microcomputadores (Notebook) e tablets. O motivo para utilização de microcomputadores pelos participantes está no tamanho da tela, já que segundo eles, é melhor para acessarem o aplicativo Facebook.

Quanto aos dias da semana, a quantidade de tempo despendido para o uso de RSV e o turno que mais utilizam, verificou-se que os 21 participantes as utilizavam todos os dias, com tempo gasto entre 30 minutos e acima de 5 horas de uso diário, geralmente pelos períodos da manhã e noite. Sobre os recursos/ ferramentas disponíveis nas RSV, predominou a utilização de mensagens instantâneas (21), seguida de fotos e vídeos (13), publicação e compartilhamento no mural do Facebook (11) e participação em grupos (8).

Quando questionados sobre quem os incentivou a criarem perfil nas RSV, constatou-se que os familiares foram os principais incentivadores para 12 participantes, seguida dos colegas de trabalho (5), enquanto para 4, o interesse partiu deles próprios. Por meio dos resultados, observou-se que a adoção das RSV pelos idosos está relacionado ao incentivo de familiares, em especial, aos filhos. Os filhos foram os principais incentivadores para 4 participantes, enquanto para 3 idosos foram os netos e cônjuge e, para 2 os irmãos e sobrinhos.

Em relação aos fatores motivadores para a utilização das RSV pelos idosos, o principal foi a possibilidade de maior comunicação com os familiares e parentes. Constatou-se que, para todos eles, a relação familiar motiva a adoção das RSV. Os fatores "contato com a família (filhos e netos)"; "acompanhar a rotina dos filhos, netos e parentes distantes"; "contato com parentes", foram 
os fatores mais citados pelos participantes. As RSV podem proporcionar aos idosos uma maior e melhor interação com os familiares.

Faz-se necessário apontar que, durante as respostas, vários aspectos implícitos foram anotados em registro de campo, como: sentimentos de nostalgia; lembrança de momentos vividos com a família; celebração festiva e rotina que foram surgindo no desenrolar das falas. Percebeu-se que esses fatores, ao contrário, todos eles carregam em si, significados que os idosos atribuem a eles, sendo muito importantes de serem considerados. A maioria $(n=14)$ dos idosos utilizavam as redes sociais virtuais para se conectarem com filhos e/ ou netos que residiam em outras localidades, sendo essa uma maneira de amenizar a saudade dos familiares, conforme apresentado em algumas falas:

[...] Foi porque era mais fácil para conversar com meus filhos. É mais fácil para conversar com eles, ainda mais que eles moram longe e não dá para ver sempre (A3).

[...] Assim no caso, você fica sabendo o que está acontecendo com a sua família o mais rápido, e, assim, você fica sabendo de todos ao mesmo tempo. Porque às vezes você ligava de vez em quando para um e de vez em quando para outro. E agora sim, no WhatsApp a gente tem um grupo, aí eles já colocam o que está acontecendo, aquele tanto de gente já vai comentando, sabe!? (A9).

[...] Por causa das minhas meninas [filhas], netos, os parentes e depois amigos. Minhas meninas em especial, né!? Porque as duas moram em Uberlândia e aqui, como se diz, só sobrou eu, por enquanto. Tem dia que tem neto, tem sobrinho, mas geralmente é só eu e Deus. E aí a gente fala todo dia pela internet, pelo Facebook, pelo WhatsApp. Eu tenho também uma netinha americana [...]. É bom demais, eu vejo foto dela toda hora, fico esperando os vídeos dela. (A10).

[...]. No caso, foi porque meus filhos não moram aqui em São Gotardo, então eles me falaram para usar também o WhatsApp porque iria ficar mais fácil conversar com eles lá. (A18).

Esses resultados são semelhantes a outros estudos encontrados na literatura. Ariyachandra, Crable e Brodzinski (2009) ao estudarem as percepções dos consumidores de mídias sociais no Canadá, identificaram que os idosos almejam maior interação com os familiares e amigos, além de ampliarem sua rede de contatos. Wasserman et al. (2012) compreenderam que a principal utilização das RSV por idosos é a possibilidade de uma comunicação mais 
ágil com os familiares. Já Chepe e Adamatt (2015), ao verificarem a interação de um grupo de idosos com o Facebook, concluíram que ela permite aos idosos expandir as formas de comunicação e compartilhamento de informações. As RSV são ferramentas que podem contribuir para que os idosos diminuam o isolamento social e, dessa forma, vivenciem um processo de envelhecimento bem-sucedido e com qualidade. Além das questões ditas, observou-se, nas falas de alguns idosos, que os fatores iam além da possibilidade de comunicação, trazendo recordações vividas em família, resgatando o passado. Possibilitavam a vivência de experiências que permitiam a recordação de momentos que marcaram alguma fase da vida.

Para conversar mais com meus filhos, meus irmãos, minha família mesmo poder ver o que eles estão vivendo, onde estão indo. Os lugares que estão passeando, né? Porque não dá para estar perto o tempo todo, então, é um meio que se usa para estar junto, sabe?! A gente acha que filho nunca cresce (risos), mas na verdade, cresce e muito rápido e dá uma saudade de quando eles estavam todos aqui, porque foi aqui que a gente viveu desde quando o primeiro nasceu. (A3).

Esse sentimento nostálgico aumentava quando refletiam que poderiam ter convivido mais com os filhos enquanto estavam residindo todos em um mesmo domicílio. Observou-se que esses sentimentos foram comuns aos participantes que saíram para o mercado de trabalho, principalmente entre as mulheres. Percebeu-se, também, que havia, além da nostalgia, um certo sentimento de culpa em algumas falas, por terem saído "de casa" para trabalharem na esfera pública, conforme indicado na fala da participante A11:

A motivação maior foi por causa da família, dos meus filhos, dos meus netos. O Beta (filho) mora lá em BH, então, principalmente com ele, que não dá para gente vê sempre, é mais fácil ter o contato. Ainda mais agora com o netinho pequeno, aí que é bom, porque dá uma vontade de ver ele crescer, de estar perto e aí, até que dá, porque pode mandar um vídeo, pode conversar, trocar fotos e ir trocando os momentos, entende? E isso é importante, porque como eu tive que ir trabalhar para ajudar na renda, eu não vivi muitos esses momentos com os meninos, então estou vivendo agora, com o Bê (neto). Aí eu penso que quero aproveitar para ver ele crescer, entende? Porque de certa forma eu não pude fazer isso com os meninos. (A11).

Após essa fala, a participante A11 interrompeu a entrevista para buscar algumas fotos. Além disso, também trouxe para perto o seu telefone celular, mostrou fotos da família e apresentou as pessoas que citava no decorrer da entrevista. A participante, como quem buscava justificar algo, mostrava, 
demonstrando alegria, as fotos e vídeos do neto que possuía no celular. Também mostrou fotos dos filhos, o que por sinal, eram muitas, distribuídas pela sala de sua casa, local em que a entrevista foi realizada. Foi notado nesse momento, que a participante não queria somente convencer a pesquisadora de que mesmo "distante", atuando no mercado de trabalho, fez sempre questão de registrar os momentos vividos pelos filhos, mas sim, justificar para ela mesma, o motivo de sua ausência em momentos que gostaria de estar perto. Para ela, as RSV permitiam a ela vivenciar, mesmo que virtualmente, momentos com os filhos, o que no passado, nem sempre foi possível. Era essa sua principal motivação para a utilização.

Em função de carregarem ainda a responsabilidade do cuidado do lar, a participação feminina na esfera pública, ainda representa para a mulher um grande desafio (AMARAL; VIEIRA, 2009). Ao passo que se sentem orgulhosas por buscarem uma melhor inserção no mercado profissional, algumas mulheres possuem um sentimento de culpa por ficarem menos tempo com a família. Carvalho Neto, Tanure e Andrade (2010) discorrem para o fato de que exista, ainda, mulheres que carregam a sensação de culpa em relação ao tempo que não puderam se dedicar aos filhos e aos cuidados com a casa.

Esse sentimento tende a ser maior na velhice, pois nessa fase, as pessoas começam a refletir sobre a vida e os papéis que poderiam ter desempenhado. Existe, também na velhice, um sentimento alto de arrependimento por momentos que poderiam ter sido vividos ou situações que gostariam que tivessem sido diferentes. Há, ainda, um sentimento de remorso na criação e educação dos filhos (RISSARDO et al., 2012). Os novos meios de comunicação, como as RSV podem contribuir para a diminuição desses sentimentos, já que possibilitam uma maior interação com os entes distantes. Outrossim, a participante A15 também expõe alguns sentimentos que foram desencadeados a partir da motivação dos filhos e parentes próximos para que a mesma criasse um perfil nas RSV:

[...]. Tudo começou quando o meu irmão veio aqui em casa passar, acho que foi o Natal. Estava a casa cheia - os filhos, irmãos, sobrinhos, aquela parentaiada toda. Assim, conversa vai, conversa vem, meu irmão falou que estava aprendendo a usar por causa do trabalho dele, mas que estava gostando muito. Minha menina ficou empolgada e começou a falar que ia me ensinar. Eu nem dei muita bola, até falei com ela "não mexo com isso não, isso é para vocês mais jovens", mas a insistência começou a ser tanta! Nem celular para internet eu tinha. Foi aí que eles começaram a falar: "mãe, todo mundo mora fora, a senhora fica muito em casa, a senhora vai gostar, até o tio tem. A senhora vai poder conversar mais com ele e aí nem precisa da gente ficar te mostrando as coisas". Porque muitas vezes, a Carol (Filha) quando vinha, me mostrava as 
fotos da família e me contava também as notícias deles. A Carol, um dia veio me ver, porque ela vem mais vezes, né? Chegou com um celular e disse "mãe, toma" e eu fiquei brava, acredita?! (Risos). Começa daqui, vai dali, e aí foi indo. Tem o grupo da família, lá está todo mundo, tem momentos que eles mandam fotos antigas para a gente recordar, matar a saudade, lembrar de coisas que às vezes a gente nem lembra mais, né? Eu penso, que se o Valter (marido) estivesse aqui, ele ia gostar bastante, ele gostava muito destas coisas, era muito curioso. Então, partiu disso tudo (risos), foi da família né? (A15).

Assim, observa-se o sentimento da saudade do cônjuge, despertado no final do relato da participante. Apesar de toda a vitalidade, "a independência dos filhos, a morte de entes queridos, de amigos e a aposentadoria, são experiências que marcam a fase da vida onde o medo de ficar só se torna central" (ALMEIDA, 2011, p. 151). Embora acredite que nenhum idoso viva isolado, seu bem-estar está ligado diretamente à disponibilidade daqueles que o cercam. Com o avanço da idade, as pessoas tendem a vivenciar um estreitamento das suas relações. Os pais assistem seus filhos saírem de casa para estudo e casamento; além disso, outras situações, como a aposentadoria, a morte de um cônjuge e a distância dos parentes contribuem para que as relações sejam mais restritas (NOGUEIRA et al., 2009).

Quanto à viuvez, Camarano (2011) constatou que essa é uma característica que predomina entre o grupo feminino. Os motivos para a proporção maior de viúvas devem-se à maior longevidade das mulheres e prevalência da cultura dos homens casarem-se novamente e, geralmente, com mulheres mais novas (CAMARANO; GHAOURI, 2002). Para algumas idosas, a morte do cônjuge se revela como trágica, desencadeando danos negativos para sua vida (ALMEIDA et al., 2015). Em muitas situações, é tratada como sinônimo de solidão.

Diante destes acontecimentos, as redes familiares e sociais contribuem para que não só as mulheres, e sim, todos os idosos recebam apoio social e emocional, possuam sentimentos de pertencimento e diminuam o isolamento social (NERI, 2005). Manter um grupo comum com os membros familiares nas RSV motivam os idosos a permanecerem inseridos nesse contexto virtual, já que em um primeiro momento, muitos acreditam ser uma realidade que não lhes pertence.

Dentre outros fatores que despertam o interesse dos idosos em relação às RSV está a vontade de pertencimento e inclusão na sociedade (CHAN-OLMSTED; CHO; LEE, 2013). Essa nova forma de comunicação permite que os idosos aumentem sua rede social, interajam e comuniquem com outras pessoas, uma vez que o processo de envelhecimento pode fazer com que as pessoas diminuam suas redes de relacionamentos devido à aposentadoria, 
isolamento, perda de membros familiares, saída dos filhos do vínculo familiar, dentre outros (FIORE et al.; 2009). Além das questões supracitadas, outro fator apontado como influenciador do uso das RSV pelos idosos foi o econômico.

\section{Ah, uai. Eu mesmo uso porque fica mais barato para mim, já tenho internet em casa, então pago só a internet e nem coloco mais crédito no celular. (A8).}

Financeiro. Se você parar para pensar, dá para resolver tudo sem precisar gastar com ligações. (A2).

Os participantes deixavam claro que o fator motivador para que eles utilizassem as RSV estava relacionado às questões financeiras. Os aplicativos Facebook e WhatsApp, possibilitam a troca de mensagens por meio de telefone celular, além do compartilhamento de arquivos de texto, vídeo e áudio, e não possui custo de utilização, basta possuir acesso a um telefone inteligente com conexão à internet (AHARONY, 2015; GAIKAR, 2015; PARK; CHO; LEE, 2014).

Constatou-se que, embora tenham mencionado possuírem as RSV Instagram, Snapchat; LinkedIn, estas raramente foram citadas no decorrer das falas dos entrevistados. Alguns, que disseram que as possuíam, como a entrevistada A21, sequer nunca as acessou, utilizando frequentemente o Whats App e o Facebook. Os demais participantes mencionaram que as motivações para o uso do Instagram, Snapchat; LinkedIn ocorreram por "curiosidade", já que possuíam o WhatsApp e o Facebook e gostariam de aprender sobre as demais. Só a participante A1 que disse que ter sido motivada a utilizar o LinkedIn por questões profissionais, que não foram por ela especificadas.

Diante dos resultados, observou-se que a população idosa pode se beneficiar do uso das RSV pela potencialização de comunicação, visando alcançar informações que são solicitadas e compreendidas sem a necessidade de custo financeiro elevado e locomoção física, estimulando suas atividades mentais (CHAN-OLMSTED; CHO; LEE, 2013). As RSV podem fortalecer as relações e interações cotidianas (BOYD; ELISON, 2007), além de possibilitar a alteração, positiva da rotina dos idosos em busca de uma melhor qualidade de vida e bem-estar, inclusive favorecendo uma melhor e maior interação familiar com membros distantes (STACHESKI, 2013). 
Evidencia-se que as tecnologias de informação e comunicação estão cada vez mais presentes na sociedade contemporânea e no cotidiano da pessoa idosa. Os indivíduos estão mudando a maneira de agir, de pensar e de se comunicar, pela integração dessas novas tecnologias a seus comportamentos. As alterações produzidas pelas intermediações tecnológicas são muitas, evoluindo de forma incessante e rápida.

No que tange aos objetivos relacionados ao uso das RSV, observou-se que a maioria dos idosos foram influenciados a adoção do mesmo em seu cotidiano por meio de eventos ocorridos no ambiente familiar, como a saída dos filhos de casa, devido à mudança de cidade, casamento e estudo. Esses eventos ocorridos fizeram com que novas formas de comunicação fossem utilizadas para que a saudade fosse amenizada e as relações se mantenham ativas.

Percebeu-se que o uso do aplicativo proporcionou aos idosos, experiências positivas, principalmente relacionadas como um recurso para entretenimento e contato com familiares e amigos. A facilidade de comunicação favorece para que os idosos possuam uma maior e melhor rede de relações, em especial, para que o contato com a família ocorra com mais facilidade e que a saudade entre os membros seja minimizada.

Entretanto, discorre-se para as limitações desse estudo, que estão diretamente ligadas à metodologia qualitativa adotada. Para minimizá-las, foram tomados determinados cuidados, com base na fundamentação metodológica escolhida. Com relação à confiabilidade, elaborou-se um protocolo de forma a sistematizar todo o conjunto de dados coletados e analisados.

Por outro lado, essa pesquisa apresenta contribuições para a comunidade científica, aos idosos, os sujeitos participantes e a academia. Para a comunidade científica, destaca-se a compreensão quais fatores motivam as pessoas idosas a utilizar novas formas de comunicação, em especial as RSV. Para os idosos, destaca-se a contribuição que o suporte teórico e a análise dos dados empíricos apresentados nesse estudo pode oferecer. Por meio dos resultados, outros idosos podem se sentir motivados a adotarem o aplicativo em seu dia-a-dia e dessa forma, terem a possibilidade de uma maior interação social, além de outros benefícios supliciados no decorrer do desenvolvimento deste estudo.

Para os sujeitos participantes, os idosos dessa pesquisa, a contribuição pode residir na oportunidade de reflexão acerca do benefício das RSV em seu cotidiano. No que diz respeito à academia, acredita-se que esta pesquisa contribui para os estudos sobre aspectos relacionados a envelhecimento, tecnologias de comunicação e qualidade de vida. 
Quanto à formulação de uma agenda para futuras pesquisas, sugere-se que sejam realizados estudos de caso comparativos em cenários diversificados, abrangendo outras regiões do país, participantes de diferentes níveis de escolaridade e classe social, de modo a ampliar as discussões considerando-se os idosos e as tecnologias de comunicação. No que refere aos aspectos metodológicos, sugere-se que outras estratégias e abordagens sejam utilizadas, contemplando a triangulação de dados, métodos e teorias, e que os participantes possam ser ampliados para outras categorias. Frente ao exposto, destaca-se que as pessoas podem, e devem usufruir de um processo de envelhecimento saudável, e que a responsabilidade por permitir isso é de toda a sociedade.

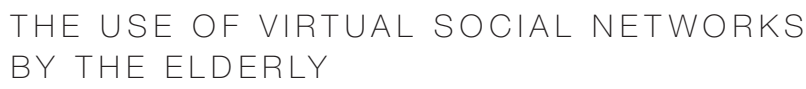

In view of the changes in the population structure, coupled with the technological changes resulting from the increase in the use of virtual social networks (RSV), people's daily lives require a better understanding of the use of these networks by the elderly. In order to carry out such an analysis, it is of great relevance that studies on the factors that motivate this public to the use of RSV are deepened. The academy began to explore the characteristic of RSV users and the reasons for their use. However, most studies have been limited to studying a specific group of users - the young - leaving, in this way, gaps regarding other age groups, such as the elderly. In addition, there is a focus on technology and innovation and not specifically on the use of RSV alone. In this context, the interest arose in conducting a research with the objective of identifying the main motivations that lead the elderly to adopt the use of RSV in their daily lives. For this, a descriptive, descriptive exploratory research was carried out, with a qualitative nature, with a sample of 21 elderly individuals with RSV profile. The results showed that the use of RSV provides the elderly, positive experiences, mainly related as a resource for entertainment and contact with family and friends. The ease of communication favors the elderly to have a greater and better network of relationships, in particular, so that the contact with the family occurs more easily and that the longing among the members is minimized. 
Elderly. Virtual social networks. Family relationships.

referências

AHARONY, Noa. What's App: a social capital perspective. Online Information Review, v. 39, n. 1, p. $26-42,2015$.

ALMEIDA, Ivana Carneiro. Terceira Idade e Consumo: experiência de consumo alimentar da classe C. 2011. 223 f. Tese (Doutorado em Administração)-Universidade Federal de Lavras, Lavras, 2011.

ALMEIDA, Edilene Joceli de et al. Dor e perda: Análise do processo do luto. Revista de Psicologia da Imed, Porto Alegre, v. 1, n. 7, p. 15-21, jan. 2015.

AMARAL, Graziele Alves; VIEIRA, Adriane. A Mulher e a Tripla Jornada de Trabalho: a arte de ser beija-flor. In: ENCONTRO DA ANPAD, 33., 2009, São Paulo. Anais... São Paulo: Anpad, 2009. p. 1-16.

ARIYACHANDRA, Thilini; CRABLE Elaine, BRODZINSKI Jay. Seniors Perceptions of the web social networking. Issues in Information Systems, v. 10, n. 2, p. 332, 2009.

AZEVEDO, Celina Dias; CÔRTE, Beltrina. Breve reflexão sobre a internet e a longevidade: novos espaços de socialização preparam o silêncio da saúde. A Terceira ldade: estudos sobre envelhecimento, v. 20, n. 45, p. 7-37, 2009.

BARBOVSCH, Monica; MACHÁCKOVÁ, Hana; ÓLAFSSON, Kjartan. Underage Use of Social Network Sites: it's about friends. Cyberpsychology, Behavior, And Social Networking, v. 18, n. 6, p. 328-332, 2015.

BARDIN, Laurence. Análise de Conteúdo. Lisboa: Edições 70, 2009.

BOYD, Danah; ELLISON, Nicole. Social network sites: definition, history, and scholarship. Journal of Computer-Mediated Communication, v. 13, n. 1, p. 210-230, 2007.

BRASIL. Lei n 10.741, de $1^{\circ}$ de outubro de 2003. Dispõe sobre o Estatuto do Idoso e dá outras providências. Diário Oficial [da] União, Poder Executivo, Brasília, DF, 3 out. 2003. Disponível em: <http://www.planalto.gov.br/ccivil_03/leis/2003/L10.741.htm>. Acesso em: 7 abr. 2016

CAMARANO, Ana Amélia; GHAOURI, Solange Kanso. Famílias com Idosos: ninhos vazios?. In: ENCONTRO DA ASSOCIAÇÃO BRASILEIRA DE ESTUDOS POPULACIONAIS, 13., Ouro Preto, 2002. Anais... Ouro Preto: ABEP, 2002.

CAMARANO, Ana Amélia. Envelhecimento da população brasileira: continuação de uma tendência. Coletiva, n. 5, jul./ago/set. 2011. Disponível em: <http://www.coletiva. org/site/index.phpopt>. Acesso em: 15 abr. 2016.

CARVALHO, Alessandra Silva. Gestão de pessoas e envelhecimento: sentido do trabalho para o idoso. In: ENCONTRO ENANPAD, 33., 2009, São Paulo. Anais... São Paulo: ANPAD, 2009.

CARVALHO NETO, A.; TANURE, B.; ANDRADE, J. Executivas: carreira, maternidade, amores e preconceitos. RAE-eletrônica, São Paulo, v. 9, n. 1, jan./jun. 2010. Disponível em: <http://rae.fgv.br/rae-eletronica/vol9-num1-2010/executivas-carreira-maternidade-amores-preconceitos>. Acesso em: 10 abr. 2016.

CHAN-OLMSTED, M. Sylvia.; CHO, Moonhee.; LEE, Sangwon. User Perceptions of Social Media: a comparative study of perceived characteristics and user profiles by 
social media. Online Journal of Communication and Media Technologies, v. 3, n. 4, p. 149-178, 2013.

CHEN, Yi-ru R.; SCHULZ, P. J. The Effect of Information Communication Technology Interventions on Reducing Social Isolation in the Elderly: a systematic review. Journal of Medical Internet Research, v. 18, n. 1, p. 18-30, 2016

CHEPE, Lucélia Moreira; ADAMATT, Diana Francisca. Estudo Sobre Interação de Idosos em Redes Sociais Virtuais. Informática na Educação: teoria \& prática, v. 18, n. 2, p. 1-22, 2015.

COMITÊ DE ÉTICA EM PESQUISAS COM SERES HUMANOS DA UNIVERSIDADE FEDERAL DE VIÇOSA. Pesquisa sobre o uso das tecnologias de informação e comunicação no Brasil: 2005-2009. São Paulo: Comitê Gestor da Internet no Brasil, 2014. Disponível em: <http://www.cetic.br/media/docs/publicacoes/2/tic-edicao-especial-5anos.pdf>. Acesso em: 1 maio 2016.

FIORE, Arlene et al. Multimodel estimates of intercontinental source-receptor relationships for ozone pollution. Journal of Geophysical Research, v. 114, n. 4, p. 1-22, 2009.

GAIKAR, V. A Guide to using Social Media Channe/s for Your Business. 2015. Disponível em: <https://www.tricksmachine.com/2015/01/guide-using-social-media-channels-business.html>. Acesso em: 20 abr. 2015.

GIL, Antônio Carlos. Métodos e técnicas de pesquisa social. 5. ed. São Paulo: Atlas, 2008. INSTITUTO BRASILEIRO DE GEOGRAFIA E ESTATÍSTICA (IBGE). Pesquisa Nacional de Amostra por Domicilios (PNAD), 2015. Disponível em: <https://loja.ibge.gov.br/ sintese-de-indicadoressociais-2014-uma-analise-das-condicoes-de-vida-da-populac-o-brasileira.html>. Acesso em: 18 abr. 2016.

LEWIS, Sam; ARIYACHANDRA, Thilini. Seniors and Online Social Network Use. Journal of Information Systems Applied Research, Chicago, v. 4, n. 2, p. 4-18, 2011.

KALACHE, Alexandre. O mundo envelhece: é imperativo criar um pacto de solidariedade social. Revista Ciência Saúde Coletiva, v. 13, n. 4, 2008.

MONTAÑA, Mireia; ESTANYOL, Elisenda; LALUEZA, Ferran. Internet y nuevos medios: estudio sobre usos y opiniones de las personas mayores en España. Revista Internacional Información y Comunicación, v. 24, n. 6, p. 759-780, 2015.

NERI, Anita Liberalesso. As políticas de atendimento aos direitos da pessoa idosa expressas no estatuto do idoso. A Terceira ldade, v. 16, n. 34, p. 7-24, 2005.

NOGUEIRA, Eliete Jussara et al. Rede de relações sociais e apoio emocional: pesquisa com idosos. Iniciação Científica CESUMAR, Maringá, v. 11, n. 1, p. 65-70, jan./jun. 2009.

PARK, Seongwon; CHO, Kwangsu; LEE, Bong Gyou. What makes smartphone users satisfied with the mobile instant messenger?: social presence, flow, and self-disclosure. International Journal of Multimedia \& Ubiquitous Engineering, v. 9, n. 11, 2014.

PEW RESEARCH CENTER. Generations 2010. Washington, DC: PEW Research Center, 2010. Disponível em: <http://www.pewinternet.org/files/old-media/Files/Reports/2010/ PIP_Generations_and_Tech10.pdf >. Acesso em: 15 abr. 2016

RESENDE, M. C. et al. Rede de relações e satisfação com a vida em pessoas com amputação de membros. Ciências \& Cognição, Rio de Janeiro, v. 10, p. 164-177, 2007.

RIDDER, Sander de; VAN BAUWEL, Sofie. The discursive construction of gay teenagers in times of mediatization: youth's reflections on intimate storytelling, queer shame and realness in popular social media places. Journal Of Youth Studies, v. 18, n. 6, p. 777-793, 2015 
RISSARDO, Leidyani Karina et al. Sentimentos de residir em uma instituição de longa permanência: percepção de idosos asilados. Revista de Enfermagem UERJ, v. 20, n. 3, p. 380-385, 2012.

ROSENBERG, Buck. Social spaces for seniors: exploring seniors' centres and clubs in Australia. Journal Of Sociology, v. 51, n. 3, p. 464-477, 2013.

STACHESKI, Denise Regina. O idoso brasileiro na comunicação pública: cidadania e representações sociais num sistema de interação midiático. 2013. 203 f. Tese (Doutorado em Comunicação e Linguagens)-Universidade Tuiuti do Paraná, Curitiba, 2013. Disponível em: <http://tede.utp.br:8080/jspui/bitstream/tede/1498/2/O\%2OIDOSO\%20 BRASILEIRO.pdf>. Acesso em: 30 mar 2016.

WASSERMAN, Camila et al. Redes Sociais: um novo mundo para o idoso. RENOTE: revista novas tecnologias na educação, Porto Alegre, v. 1, n. 10, p. 1-10, jul. 2012.

Data de submissão: 01/07/2017

Data de aprovação: 26/01/2018 